Research Article

\title{
Understanding Customer Value in the Mobile Internet Era
}

\author{
Jing Li $\mathbb{D}^{1}{ }^{1}$ Ayenew Darge Nigatu, ${ }^{1}$ Baoquan $\mathrm{Yu}^{2}{ }^{2}$ Qiaolun $\mathrm{Gu},{ }^{1}$ and Yong Yang ${ }^{1}$ \\ ${ }^{1}$ School of Economics and Management, Tianjin University of Technology and Education, Tianjin 300222, China \\ ${ }^{2}$ China Postal Express\& Logistics Co. Ltd, Beijing 100032, China
}

Correspondence should be addressed to Jing Li; lijingjing@tute.edu.cn

Received 14 October 2021; Revised 3 November 2021; Accepted 10 November 2021; Published 29 November 2021

Academic Editor: Daqing Gong

Copyright ( 2021 Jing Li et al. This is an open access article distributed under the Creative Commons Attribution License, which permits unrestricted use, distribution, and reproduction in any medium, provided the original work is properly cited.

\begin{abstract}
The advent of mobile Internet era brings both opportunities and challenges to understanding customer value in the field of customer relationship management. Traditional customer relationship management theory and practice focus on the transaction value created by individual customers and do not take into consideration enough to the huge potential commercial value behind the interaction and connection among people by means of online social services in the mobile Internet era. Towards this end, this study first analyses the new characteristics of customer behaviour in the mobile Internet era. Second, the study proposes the integrated customer value model in three dimensions of purchase value, interactive value, and marketing diffusion value with 13 indicators based on the complex network theory and RFM model, considering the value created by connection and interaction among customers. Finally, the study discusses the eight types of customer clusters and the corresponding differentiate customer relationship management strategies in the era of mobile Internet based on the integrated customer value model. This study enriches the theory of customer value in the field of customer relationship management and also helps company better practice the innovation and change in the management of relationship with customer in the mobile Internet era.
\end{abstract}

\section{Introduction}

Mobile Internet breaks the limitation of time and space and is changing the way of not only people's communication but also purchase. People can make a purchase anytime and anywhere by electronic commerce application on the mobile smart device accessing to the Internet. Besides conveniently shopping online, more and more people make use of the fragmented time to share product experience, marketing information related to brand, and even complaints of products in texts, pictures, web page links, and short videos with other people on the social media anytime and anywhere. The information on their sharing related to the brand spreads rapidly and broadly on the social media by forwarding from other people and also influence on the purchase decision of the other potential customer by means of their online influencing power. The role of consumer (we use the terms "consumer" and "customer" interchangeably throughout the paper) in the relationship with the company becomes different as the changing of customer behavior in the era of mobile Internet. A consumer is not just a contributor to the company's revenue but also an important partner of company in marketing promotion. The new trend of relationship of customer and company in era of mobile Internet brings both opportunity and challenge to the theory and practice of customer relationship management, especially in the field of understanding customer value.

Understanding customer value is important for a company to manage the relationship with the customers. The value created by customers is differentiate, although the importance of each customer cannot be ignored. The Pareto Law of Vilredo Pareto pointed out that $80 \%$ of the profits of companies created by $20 \%$ of customers. Only when restricted resources are invested in the customer relationship that can brings values to company, can it win the maximum profit [1]. Scholars commonly identified the customer value from the perspective of transaction. The initial research on customer value mainly focused on the revenue or profit created at the current time point of customers. Sviokla and Shapir [2] defined customer value as the difference between the amount of customers' consumption of products and the cost paid by the company in this process. Reichheld [3] 
defined customer value as the net cash flow brought by customers in the present which comes from five sources, base profit, revenue growth, cost saving, referrals, and price premium. With the gradual deepening of the research on customer value, scholars realized the limitation of just considering the profits created by customer in the present when understanding the customer value, which would lead the company to pursue quick success and be not conductive to the long-term development in the management of customer relationship. Therefore, the potential contribution of customers to company was surfaced. Barbara put forward the concept of customer lifetime value and identified it from net present value of monetary created by customers at present and in the future. Bitran and Mondschein [4] introduced the concept of customer life cycle and defined customer value as the discounted present value of the net profit generated by the customer in its full life cycle. Since then, scholars have expanded and enriched the concept and valuation of customer value, including the NPV model based on customer life cycle [5], Pareto/NBD model [6, 7], and RFM model $[8,9]$. Although scholars have different understanding of the customer value, they all pay attention to the value created by customer in the relationship of transaction with the company.

The research on customer value in the field of customer relationship management has made rich achievements; however, there are still some gaps to fill when understanding customer value in new era of mobile Internet. Traditional customer relationship management focuses on keeping a long-term continuous transaction between customer and company in the market, that is to say, a customer's value is decided by the direct monetary value created by purchase as a consumer. The great potential business value behind the behavior of customer's sharing and interactive with others as a partner of company is not taken into enough consideration. On the other hand, a customer is usually regarded as an individual who is independent of the others when identifying and assessing value customer creating, while the value creating from the connection as a member in a group of social network is rarely considered.

To enrich the research on customer value and also help company better practice the innovation and change in the management of relationship with customer in the mobile Internet era, this study tries to discuss two issues as follows:

(i) What is the new value customer create for company according to the features of customer behavior in the mobile Internet era?

(ii) How to identify those new customer value and apply it to customer relationship management practice?

Based on the above problems, this paper first analyzes the new features of customer behavior to be a foundation for identifying source of customer value in the mobile Internet era. Second, we propose integrated customer value model in three dimensions of purchase value, interactive value, and marketing diffusion value with 13 indicators based on the complex network theory and RFM model, considering the value created by the interaction and connection among customers from the perspective of a member in a group of the social network. Finally, this study discusses the eight types of customer clusters and the corresponding differentiate customer relationship management strategies in the era of mobile Internet based on the integrated customer value model.

\section{Literature Review}

2.1. Customer Value. The scholars and practical operators mainly understand customer value from the three perspectives which correspond to different subject of perceived value, respectively. (i) Customer value in the perspective of customer. Customer is the subject of perceived value in this perspective. Customer value is defined as the customer's overall perceived valuation of products and services after the trade-off between the perceived benefits and costs in the process of obtaining and consuming them [10]. Researches in this perspective that are developed from the theory of customer perceived value put forward by Zeithaml in 1988 emphasize on how to understand and meet the customer's demand and correspondingly design, make, and communicate the marketing offering. (ii) Customer value in the perspective of company. Company is the subject of perceived value in this perspective. A customer's value is decided by his or her contribution to company's survival and development, such as reducing operating expenses or increasing profits of the company $[11,12]$. The conception of customer asset and customer lifetime value is derived from this perspective. The researches in this perspective endeavor to identify and valuate the value customer creating for company, and on this basis to make the differentiated customer relationship management strategies under marketing resource constraints. (iii) Customer value in the perspective of cocreation. The concept of value cocreation between firm and customers is proposed. Firm and customer are regarded as a community of shared interests in this perspective. The value creation system of producers has evolved into an open system, and consumers have gradually changed from passive acceptors of products/services to proactive value cocreators, participating in the process of value creation of company, and cocreating personalized, unique, and differentiated consumer experience with producers [13-15]. Customers are not only single final consumer but also important partners who are participating in the process of value creation of company. Researches on understanding the customer value from this perspective are few and mainly focus on how to create customer experience and what the company can offer in the process of value cocreation.

Based on the above perspectives of understanding customer value, we propose that consumer is not just the one whose demand of product or service is met by the company, but an important partner who participates in the value creation process of company with great enthusiasm. Therefore, customer value in the present study is regarded as customer's positive contribution to the survival and development of the company as a partner from the perspective of value cocreation. 
2.2. RFM Model. The RFM model was proposed by Arthur Hughes of the American Database Marketing Research Institute [8]. This model identifies the customer value from the perspective of transaction by three types of purchase data: recent consumption (recency), consumption frequency (frequency), and consumption amount (monetary). Recency is the last time of customer purchased within a certain period of time. Frequency is the number of customer's purchases within a certain period of time. Monetary represents the total amount of customer purchased within a certain period of time. A customer would show the high-value feature when his or her latest consumption time is closer, the number of consumption is higher, and the total consumption amount is larger. For such customers, the company should pay attention to in the relationship with them.

RFM model has been widely applied in many industries, including nonprofits and financial organizations $[16,17]$, government agencies [18], online industries [19, 20], telecommunication industries [21], travel industries [22], and marketing industries [23]. RFM model is also modified to analyze the online review behavior and valuate the influential strength of the reviewers [19]. Recency was interpreted as the time range between the current date and the latest written date of a reviewer, and frequency indicated the number of writings of an author during a specific time range.

2.3. Complex Network Theory. A complex system is composed of a large number of heterogeneous elements, and these elements are connected by a variety of interactions. The complexity of a system can be reflected by the number of elements and the interaction between elements [24]. The more the number of elements, when the interaction between elements is highly nonlinear, the higher the complexity of a system. A complex network can be mapped by the component elements as network nodes and the interaction between elements as network edges of a complex system. The properties and functions of the complex system can be understood by analyzing the interaction between elements and the characteristics of network structure. Social network is a special kind of complex network, which is used to explain the characteristics of human social relations and behavior. A node in a social network represents a social actor, which can represent a person or an organization in a real social system or a user or a network account (ID) in a virtual social network. Links in social networks represent some relationships between social actors. These relationships can be genetic relationships in a biological sense, kinship relationships, geographic relationships, and can also be relationship in virtual users following, forwarding information, and comment in online social network.

Scholars have verified that online social network formed by social media and virtual community has small world effect and scale-free attribute $[25,26]$. (i) Small world effect: small world effect is the basic attribute of complex social network, which is characterized by calculating the average distance and agglomeration coefficient of the network. Compared with the ER random network, social network shows the features of small average distance and large clustering coefficient [27]. In other words, the phenomenon of small world reflects that two people who do not know each other are always connected through certain connections [28]. According to Facebook research data in 2016, the average distance between people on the online social network is 3.57 people. (ii) Scale free attribute: the scale-free is the degree distribution of a complex social network obeying the powerlaw distribution [29]. It means that only a small minority of nodes have a large number of connecting edges in the social network. That is to say, the relative position of individuals in social network is significantly differentiated, and a small minority of individuals play more important role in a social network. Those nodes are called "special node," and their influence strength can quickly spread to the most other nodes in the network [30] and also would lead to the collapse of the whole network when they are attacked or blocked [31, 32]. For example, a message posted by a small minority of influential people in the social media can quickly spread throughout the corner of the world [33], and another case is only $1 \%$ of the companies control $40 \%$ of the global economy [34].

There are four main kinds of methods to determine the importance of a node in the network, the method based on the nearest neighbor of the node, based on the path, based on the eigenvector, and based on the deletion or contraction of the node. The common measurement indexes for the importance of a node in the network are shown in Table 1 [35]. Degree centrality is one of the most commonly used indicators based on the method of nearest neighbor. It examines the importance of nodes in the network by the number of their neighbors. More neighbors a node has, the more neighbors it can directly influence, and the more important it is. Closeness centrality, betweeness centrality, and Katz centrality are the indictors based on the method of path. Betweeness centrality and Katz centrality calculate the average distance between the current node and other nodes and examine the importance of the node in the network by indicating the average spread length of information. Betweeness centrality is the number of shortest paths through the current node among the shortest paths of all pairs of nodes in the network. The more the shortest paths pass through a node, the more important that node is. It describes the controlling power of nodes on the network flow transmitted along the shortest path. Eigenvector centrality and PageRank are the indicators based on the eigenvector. The core idea of this method takes into consideration the quality of neighbor nodes besides the quantity of them. That is, the importance of a node depends both on the number of neighbors and on the relative significance of each neighbor node.

\section{Customer Value Model in the Mobile Internet Era}

3.1. New Features of Customer Behaviour in the Mobile Internet Era. Business model in the mobile Internet era presents new features of the deep integration of mobile social commerce. Mobile social commerce is the present and the future of e-commerce [36]. More and more merchants realize the importance of the social network and make use of the mobile social network as channels of sales and 
TABLE 1: Some indexes to describe the importance of nodes in the network.

\begin{tabular}{|c|c|c|}
\hline Method & Calculation formula & Description \\
\hline $\begin{array}{l}\text { Degree } \\
\text { centrality }\end{array}$ & $C^{\mathrm{DEG}} V(i)=\operatorname{deg}\left(V_{i}\right) / n-1$ & $\begin{array}{l}\text { The average influence between the } \\
\text { current node and adjacent nodes }\end{array}$ \\
\hline $\begin{array}{l}\text { Closeness } \\
\text { centrality }\end{array}$ & $\begin{array}{c}\mathrm{CP}^{\mathrm{CLO}} V(i)=1 / \sum g_{i j}^{\prime}\left(g_{i j}^{\prime} \text { represents the shortest path length from node } i \text { to }\right. \\
\text { node } j)\end{array}$ & $\begin{array}{l}\text { The difficulty of the current node to } \\
\text { other nodes, that is, the distance to other } \\
\text { nodes in the network }\end{array}$ \\
\hline $\begin{array}{l}\text { Betweenness } \\
\text { centrality }\end{array}$ & $\begin{array}{c}\mathrm{CP}^{\mathrm{CLO}} V(i)=\sum_{s<t}\left|\left\{g_{s t}^{i}\right\}\right| /\left\{g_{s t}\right\} / n(n-1) / 2\left(\left|\left\{g_{s t}^{i}\right\}\right| \text { denotes the number of }\right. \\
\text { nodes } i \text { in the shortest path between nodes } s \text { and } T\end{array}$ & $\begin{array}{l}\text { The importance of current node in the } \\
\text { whole network to be a "bridge" }\end{array}$ \\
\hline $\begin{array}{l}\text { Eigenvector } \\
\text { centrality }\end{array}$ & $\begin{array}{c}\lambda_{x i}=\sum_{j=1}^{n} a_{i j} x_{j} \text { (of which } \lambda \text { is the largest eigenvalue of the adjacency matrix, } \\
\qquad i=1,2,3, \ldots, n)\end{array}$ & $\begin{array}{l}\text { The influence of the current node is the } \\
\text { linear sum of the influence of neighbour }\end{array}$ \\
\hline PageRank & $\begin{array}{l}\operatorname{PR}\left(v_{i}\right)=(1-d / n)+d \cdot \sum_{V \in B(U)} \operatorname{PR}\left(V_{i}\right) / \operatorname{Out}\left(V_{i}\right) \text { (where } \operatorname{Out}\left(V_{i}\right) \text { is the set of } \\
\text { outgoing nodes of the node, and } d \text { is the empirical parameter, usually } 0.85 \text { ) }\end{array}$ & $\begin{array}{l}\text { The influence ranking of the current } \\
\text { node is obtained by iterative calculation }\end{array}$ \\
\hline Katz centrality & $C^{\text {kat }}\left(V_{i}\right)=\sum_{k=1}^{\infty} \sum_{j=1}^{\infty} \alpha^{k}\left(A^{k}\right) i j+\beta$ (where $\alpha$ and $\beta$ are both constants) & $\begin{array}{l}\text { The influence of the current node } \\
\text { depends on the random walk path from } \\
\text { this point }\end{array}$ \\
\hline
\end{tabular}

promotion. With the changing of the traditional PC to intelligent mobile device, people purchase, comment, and share their experience through mobile social network, which shows the new features of consuming behavior in the mobile Internet era.

\subsection{1. "Go Shopping" Changes to "Be Shopping".} Consumers visit online stores by smart phone accessing the seamless mobile Internet anytime and anywhere. Vast arrays of goods information (pictures, web page links, short videos, etc.) come to the eyes. Customers easily purchase online, adding the goods to the e-shopping cart, submitting the order, paying, and finally receiving the goods. Consumers can also directly scan the QR code offline, quickly access to the online to obtain information and place orders, and then pick up goods and service offline. Consumers can switch offline and online seamlessly easily in the whole process. Consumer demand is more fully responded, and purchase intention can be evoked easily in various situation $[37,38]$. Shopping is not only consuming behavior but also becoming increasingly a social tool to communicate with other people, for example, customers can find the product or service they need by browsing WeChat friend circle in their short leisure time and start a quick talk about the product theme with the friends on social media.

3.1.2. Interaction Is Everywhere. People make use of fragmented time such as waiting, travel, eating, and bed time to create, share information, and interact quickly. Consumers make online comments on the goods and services they buy, including the quality of products, after-sales service, and overall satisfaction and also share their feelings and experiences through text, pictures, or short videos by means of social tools such as Facebook, WeChat, and Tik-Tok. There is a strong or weak social relationship between the information publisher and the receiver. Compared to the direct advertising from the company, the special trust from this relationship makes the sharing related to the brand from a customer having a more influence on persuading the potential customer to be a real one.
3.1.3. Powerful Diffuser of Marketing Information. Individuals are no longer just consumers and information content producers, but also diffusers of marketing information in the era of mobile Internet. Every consumer can establish the circle of interest and further build their own social network by means of social tool. With the help of people and social network, marketing information is sustainably created and recreated, secondarily forwarded and diffused in a way of the fission, ultimately achieving marketing information explosive spreading widely in a short time. That is to say, marketing information can be known by large numbers of people in almost "every corner of the world in one night."

3.2. Customer Value Model in the Mobile Internet Era. In this paper, the customer value is defined as customer's contribution to the survival and development of company as a partner from perspective of value cocreation. Based on the analysis on the new features of consumer behavior in the era of mobile Internet, purchase behavior, interactive, and sharing behavior, marketing information diffusion behavior is regarded as the three main sources of value customer creation as shown in Figure 1.

Therefore, this paper constructs an integrated customer value model in the era of mobile Internet from three dimensions of purchase value, interactive and sharing value, marketing information diffusion value and builds specific indexes and calculation methods combining with the RFM model and complex network theory. The detailed analysis and calculation are as follows.

3.2.1. Purchase Value. Purchase value refers to the direct value that customers create for company through their real purchase behavior. It is an important dimension to identify the customer value. Based on the RFM model, this study identifies and valuates customer purchase value from the three indicators of customer transaction relationship duration, purchase frequency, and average consumption amount. The longer the customer transaction relationship lasts, the higher the purchase frequency and the average 


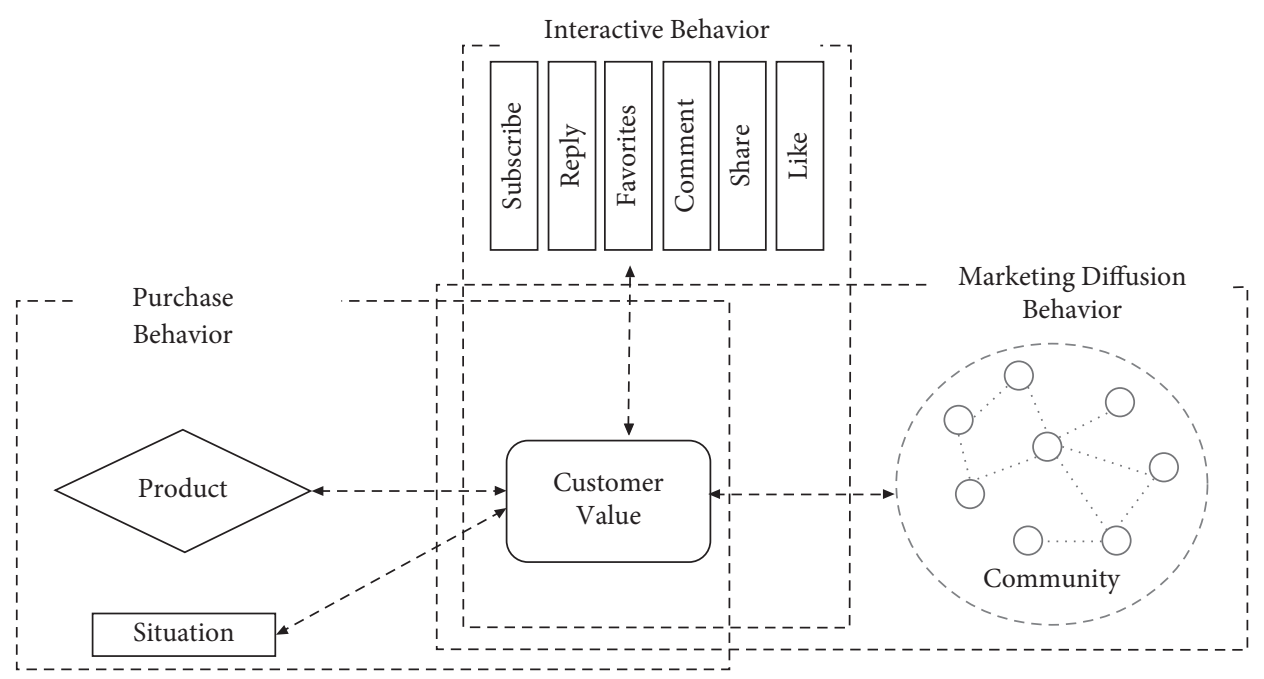

Figure 1: The source of customer value in the mobile Internet era.

consumption amount, the higher the purchase value of the customer. The specific conception and calculation method of indicators are as follows.

\subsubsection{Transaction Relationship Duration. The R in the RFM} model is defined as the customer's last consumption time during the statistical period. Hughes found that the later this time is, the higher the possibility that the customer will consume again. However, this indicator cannot distinguish between new and old customer. Even if the latest purchase time of two customers is the same, their values may be totally different. The customer may have a long-term trading relationship with the company or it may also just start. Therefore, transaction relationship duration is posed to replace the latest purchase time (R) in the RFM model, which is, the length of time from the first purchase to the latest purchase in the statistical period. It is a signal that a customer has deep trust and satisfaction in products and services when keeping a long-term and continuous trade relationship with company. Such customers are identified with high value. The company should devote more energy to retain the relationship with those customers. The calculation formula is as follows:

$$
\operatorname{TRD}(i)=T(i)_{1}-T(i)_{0}
$$

$\mathrm{TRD}(i)$ is the total duration of the transaction relationship between customer $i$ and the company. $T(i)_{1}$ is the time of the last purchase of customer $i$ during the observation period, and $T(i)_{0}$ is the time of the first purchase.

3.2.1.2. Purchase Frequency. Purchase frequency is the total number of purchases during the statistical period. And, it is an important indicator to measure customer purchase value. Increasing the number of customer purchases means to capture market share from the competitors in the market. It can also reflect customer's trust and loyalty to the brand. The index is calculated as follows:

$$
\mathrm{PF}(i)=f(i)
$$

$\mathrm{PF}(i)$ is the total number of successful transactions $f(i)$ of customer $i$ during the statistical period.

3.2.1.3. Average Purchase Amount. Consumption amount is an important indicator to identify the purchase value of the customer. A customer spending a large amount of money on products and services of the company contributes great income to company; on the other hand, it reflects the enough trust and reliance of customer on the products and services. This type of customer is of great value to the company. Considering the information overlap of purchase frequency and total purchase amount in the RFM model, this paper takes average purchase amount to replace the total purchase amount. The larger the average amount of the customer's purchase, the greater the purchasing power of the customer, which can bring more value to the company. The index is calculated as follows:

$$
\operatorname{APM}(i)=\frac{M(i)}{f(i)}
$$

$\operatorname{APM}(i)$ is the average purchase amount of customers in the statistical period, $M(i)$ is the total amount of purchase by customer $i$ in the statistical period, and $f(i)$ is the total number of transactions between customer $i$ and the company during the statistical period.

In summary, the total purchase value of customer $i$ in the statistical period is calculated as follows:

$$
\operatorname{PV}(i)=\alpha_{1} * \operatorname{TRD}(i)+\beta_{1} * \operatorname{PF}(i) \gamma_{1} * \operatorname{APM}(i)
$$

where $\alpha_{1}, \beta_{1}$, and $\gamma_{1}$ is the corresponding weight of $\operatorname{TRD}(i)$, $\operatorname{PF}(i)$, and $\operatorname{AMP}(i)$. The purchase amount of a customer is regarded as more value to the company in the traditional way. However, the competition of acquiring customers is intensely fierce among e-commerce platforms since e-commerce business mode tends to be mature in the era of mobile Internet, which leads to the increasingly rising customer management cost. The retaining of the customers 
becomes quite important for a company. The transaction relationship duration and purchase frequency of customers reflect the loyalty to the company and are the same important to purchase amount. Therefore, this paper assumes that the weights of the three indicators are equally important and sets the criteria of $\alpha_{1}=\beta_{1}=\gamma_{1}=1$. The final purchase value of customer $i$ is calculated as follows:

$$
\operatorname{PV}(i)=\operatorname{TRD}(i)+\operatorname{PF}(i)+\operatorname{APM}(i)
$$

3.2.2. Interactive Value. Customer interactive value refers to the contribution of customers to the company in the interaction on social network. Customer interaction behaviors mainly include like, share/forward, comment/reply, favorite, and subscription. Different interactive behaviors have different levels of customer engagement [39] as shown in Figure 2. The behaviors of comment, share, subscribe, and favorites show the stronger engagement of customer. Existing studies have confirmed that consumer's comment and sharing have significant effects on online purchase intention of potential customer and market performance of the company [40-43]. Therefore, customer interactive value is mainly identified from comment and sharing in present study. The specific identifying indicators are proposed by the improved RFM model of Li et al. [19].

3.2.2.1. Comment Value. Online shopping often brings uncertain risk to consumers because of the asynchronism of logistics and capital flow. In addition to e-commerce platform reputation and product brand, online comment from customer who has purchased is an important clue for other potential customer to reduce the risk of online shopping when making decision of purchase. Scholars have confirmed that comments/replies from the customer who purchased are more reliable and easier to be accepted by potential consumers compared with direct marketing persuasion by company. Therefore, comment value is an important factor of identifying customer value in the era of mobile Internet. The comment value is measured in this study by latest comment time, comment frequency, favorable rate, and online comment content quality based on the improved RFM model.

(i) Latest comment time: the latest comment time is the days between the last comment time and the current observation time. It indicates that the customer just made a comment recently if the value of this indicator is small, showing a high degree of customer activity and good timeliness of comment. The index is calculated as follows:

$$
\operatorname{LCT}(i)=t_{1}-t_{0}
$$

$T_{1}$ is the latest comment time of customer $i$ in the observation period, and $t_{0}$ is the current observation time.

(ii) Comment frequency: comment frequency refers to the number of comments on products and services

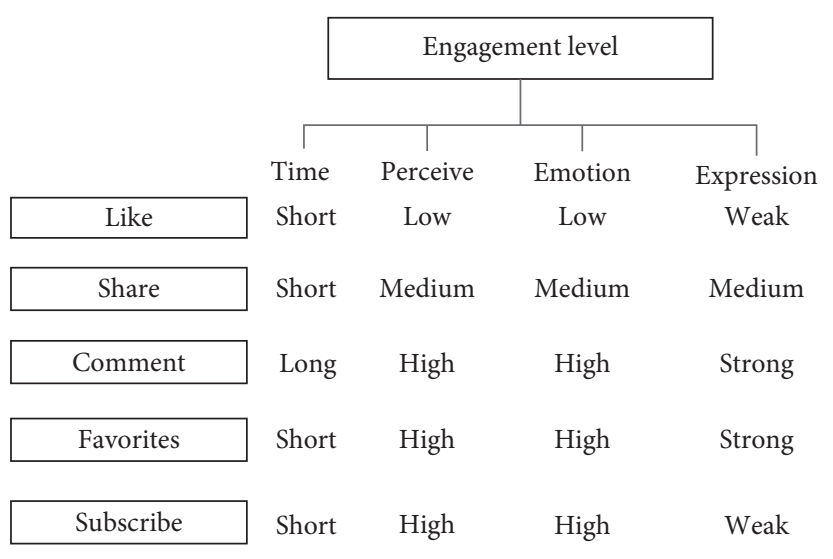

Figure 2: People's engagement level of interaction behavior [39].

by customers during the statistical period. The more the customers comment, the more they are active and have a higher tendency to continuous comment in the future. The index is calculated as follows:

$$
\mathrm{CF}(i)=c f(i)
$$

$c f(i)$ is the total number of online comments made by customer $i$ during the statistical period.

(iii) Favorable rate: Favorable rate is the ratio of the number of good rate on products and services to the total number of ratings. This index implies customer's recognition of products and services of the company and predicts the high probability of continuous purchase behavior and also has positive influence on purchase intentions of other potential consumers [44]. Customers with such characteristics have a higher value for the company. The index is calculated as follows:

$$
\mathrm{FR}(i)=\frac{\mathrm{GF}(i)}{\mathrm{CF}(i)},
$$

where $\mathrm{GF}(i)$ is the total number of positive comments of customer $i$ and $\mathrm{CF}(i)$ is the total number of comments of customer $i$.

(iv) Comment quality: good-quality online comment is often more likely to be adopted, which provides high reference value to the potential customers. The principal features of a good-quality online comment are the completeness and the timeliness of information offered [45]. Therefore, this study proposes the length of the text in the comment to measure comment quality during the observation period. The longer the content of comments, the more information it contains, the more it helps to reduce the uncertainty in potential customers' purchase decisions. The comment with such a kind of feature provides a good purchase reference for other potential customers turned to be real customers. The customer who often makes high-quality comment is regarded as an important value contributor to the 
company in this study. The index is calculated as follows:

$$
\mathrm{CQ}(i)=\frac{t f(i)}{\mathrm{CF}(i)},
$$

where $t f(i)$ is the total number of words in the online comment text of customer $i . \mathrm{CF}(i)$ is the total number of comments by customers $i$ during the statistical period.

This paper assumes that the weights of the four indexes are equally important, and CMV(i) of the $i$ th customer's comment value is calculated as follows:

$$
\mathrm{CMV}(i)=\mathrm{LCT}(i)+\mathrm{CF}(i)+\mathrm{FR}(i)+\mathrm{CQ}(i) .
$$

3.2.2.2. Sharing Value. Customers are used to learning about products and services by online comment in the prepurchase stage and sharing their consumption experience on social media in the postpurchase stage. The customer sharing value is identified by the latest sharing time, willingness to share, and sharing frequency based on the developed RFM model.

(i) Latest sharing time: the latest sharing time refers to the time interval between the last time and the current statistical time customer $i$ shares or forwards information about products and services on social media. The index is calculated as follows:

$$
\operatorname{LST}(i)=N-L(i)
$$

where $N$ is the current time and $L(i)$ is the latest sharing or forwarding time.

(ii) Willingness to share: willingness to share is whether customers are willing to share information about products and services on social media. The index is as follows:

$$
\mathrm{SW}(i)=\frac{\mathrm{SN}(i)}{\mathrm{PF}(i)}
$$

where $\mathrm{SN}(i)$ is the number of customer's sharing and $\mathrm{PF}(i)$ represents the total number of purchases by the customer.

(iii) Sharing frequency: sharing frequency is the total number of customer sharing and forwarding information about products and services on social media. It reflects the customer's preference and loyalty to the brand. This index is calculated as follows:

$$
\mathrm{SF}(i)=s f(i),
$$

where $s f(i)$ represents the total number of sharing and forwarding by the customer.

This paper assumes that the weights of the three indicators are equally important, and $\mathrm{SV}(i)$ of the $i$ th customer is calculated as follows:

$$
\mathrm{SV}(i)=\mathrm{LST}(i)+\mathrm{SF}(i)+\mathrm{SW}(i) .
$$

To sum up, the customer interactive value in the era of mobile Internet is calculated as follows:

$$
\mathrm{IV}(i)=\alpha_{2} * \mathrm{CV}(i)+\beta_{2} * \mathrm{SV}(i),
$$

where $\operatorname{IV}(i)$ is the customer's interactive value, $\mathrm{CV}(i)$ is the customer's comment value, SV(i) is the customer's sharing value, and $\alpha_{2}$ and $\beta_{2}$ are their corresponding weights. This paper assumes that $\alpha_{2}=\beta_{2}=1$, then the interaction value of customer $i$ is stated as follows:

$$
\mathrm{IV}(i)=\mathrm{CV}(i)+\mathrm{SV}(i) .
$$

3.2.3. Marketing Diffusion Value. Marketing diffusion value is the value created by the marketing information diffusion behavior of customer. People forward the marketing information related to brand, products, and services, and spread virally from 1 to $n$ and then from $n$ to $n$ by means of online social network. Marketing information reaches to the target customers quickly with the low cost, as shown in Figure 3. Marketing information includes not only the advertisement released by company but also the messages related to products and services spontaneously created and released by customers. Different position of nodes in the social network has different effects on information diffusion [46]. Some central nodes can produce larger information cascades than the other nodes, while once they are lost or blocked, the spread of information would be broken [47]. One of the solutions to maximize the effect of marketing information spreading is to identify the nodes with such a kind of special position in the social network and to motive their intention of publishing or forwarding information [48]. Complex network analysis provides a helpful tool to measure and find out those central nodes. The importance of node is also called "centrality" in complex network, and its main point is that the centrality of a node is equivalent to the significance of the connection between this node and other nodes in the network [49]. We identify marketing diffusion value of customer from three indicators of degree centrality, eigenvector centrality, and betweeness centrality by drawing on the method of node ranking in the complex network $[35,50]$.

In this paper, customer $i$ is regarded as one of nodes $(V)$ in the social network, and the following relation between people constitutes the edge $(E)$ of the network. If people A follows people $\mathrm{B}$, there is an edge pointing from $\mathrm{A}$ to $\mathrm{B}$, forming a directed graph $G(V, E)$. The in-degree of node $i$ represents the number of followers of customer $i$, and outdegree is the number of attention of customer $i$ in the social network.

3.2.3.1. Degree Centrality. The degree centrality of a node is the number of other nodes directly connecting with it in the network. The node has a high degree centrality when being connected directly by a great number of other nodes. This kind of nodes with high degree centrality is considered to be 


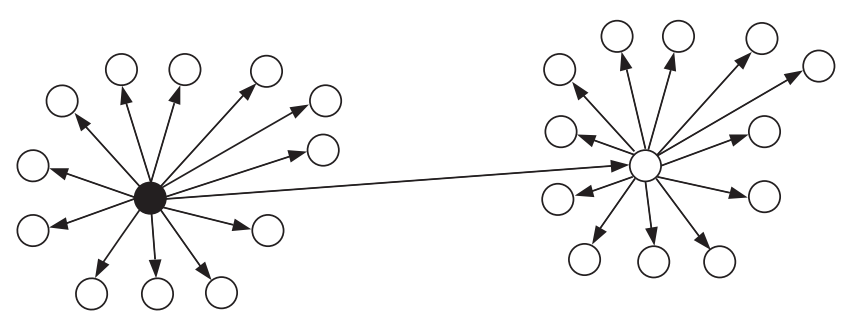

FIGURE 3: Schematic of marketing information diffusion. Note: the black solid node is the current initial publisher of marketing information, the hollow nodes are the other users, and the arrow represents the direction of information flow.

in the center of the network and has high influential power to the other nodes in social network [51]. As show in Figure 4 , node 1 is directly connected by nodes $2,3,4$, and 5 , it has the highest degree centrality $(\mathrm{DC}=4)$ in this simple network and is considered to be more value and greater influence than nodes 2, 3, 4, and 5 .

People with a high degree centrality has more followers, that is, more information receivers. The marketing information published and forwarded by such customers can reach to a larger group of audiences in the short time. On the other hand, the people represented by such nodes usually have the characteristics of opinion leader. The speech and behavior of them in social network are often followed and imitated by others and have great influence on the consumption decisions of other customers. The loss of such customer not only means loss of just a single customer but leads to the loss of a large group of customers connecting with it. The degree centrality of customer $i$ is calculated as follows:

$$
\mathrm{DC}(i)=K_{i} .
$$

$K_{i}$ represents the total in-degree of customer $i$, that is, total number of followers of the customer $i$ in social network.

3.2.3.2. Eigenvector Centrality. Some scholars have proposed a method to identify the relative position of node in a complex network based on eigenvector. The basic idea is that the importance of a node depends on not only the quantity but also the quality of the neighbor node connected with $[35,50]$. As shown in Figure 5, node $C$ is only pointed by neighbor node $\mathrm{B}$, and the in-degree of it is less. However, node $B$ is pointed by other 6 neighbor nodes, playing a more important role in this network. According to eigenvector centrality, the position of node $\mathrm{C}$ is higher than node $\mathrm{E}$ although the in-degree of node $\mathrm{C}$ is smaller than node $\mathrm{E}$. In other words, the node with a small in-degree could be important if it is directly connected by the nodes with a large in-degree.

Customers with a high eigenvector centrality usually are followed by people with the characteristic of high influence such as Internet celebrity or public opinion leader although the number of them is few. Such customers could have an indirect and important positive influence on the diffusion of marketing information by means of the people with high social influence. PageRank is the most famous improved

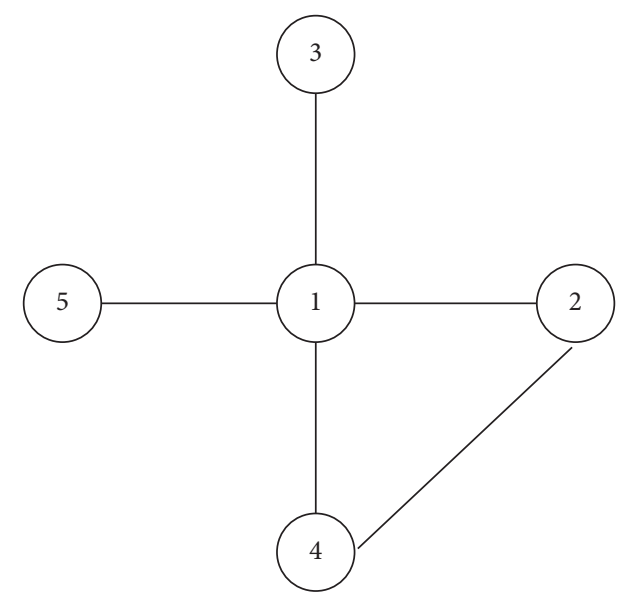

FIGURE 4: Schematic of degree centrality of node.

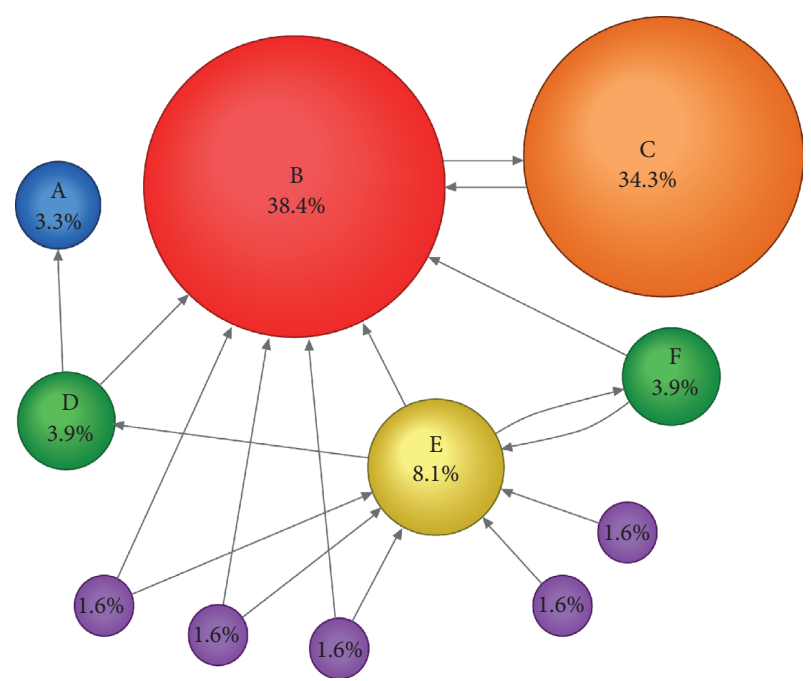

FIgUre 5: Schematic of eigenvector centrality of node. Note. The figure of percentage in the circle represents relative importance of the node.

algorithm of eigenvector centrality [35]. This paper makes use of PageRank value to measure eigenvector centrality of customers, and the calculation is as follows:

$$
\operatorname{PR}(i)=\frac{1-d}{N}+d \sum_{v \in B(u)} \frac{\operatorname{PR}(V)}{\operatorname{Out}(V)},
$$

where $\mathrm{PR}(i)$ represents the PageRank value of customer $i$ in the observation period, $d$ represents the damping coefficient, $1-d$ represents the random jump probability of customers, $N$ represents the total number of customers in the network diagram, $B(u)$ represents the set of other customer $V$ pointing to current customer $i$, and $\operatorname{Out}(V)$ represents the set of customer $V$ linked to the others.

3.2.3.3. Betweenness Centrality. Betweenness centrality of a node is the number of shortest paths through the current node among the shortest paths of all pairs of nodes in the network. Betweenness centrality characterizes the control of 
a node over the information flow transmitted along the shortest path in the network [52]. As shown in Figure 6, node A has high betweenness centrality and is an important intermediary for information exchange between group 1 and group 2. If node $\mathrm{A}$ is breakdown, there will be no information traffic among all nodes in groups 1 and 2. Although the degree centrality and eigenvector centrality of node A may not be the largest in the network, it is still of great important and play a role of a "bridge" for information transmission and circulation.

Compared with the people with high degree centrality, the people with high betweenness centrality do not have a relatively large number of followers, but they can control the information flow and business opportunities in the social network (Freeman, 1997) [53]. Although the influence of this kind of customers may not be as good as that of "opinion leaders," they are the controllers of information dissemination of several small subnetwork groups in the whole network and have an important impact on the scope of marketing information diffusion. Such people are often the key of crossing the group with the different social cycle in the marketing communication. If they are churn, they will cause immeasurable losses to the marketing communication of company in the mobile Internet era. The betweenness centrality of the customer $i$ is measured as follows:

$$
\mathrm{BC}(i)=\sum_{i \neq s, t} \frac{g_{s t(i)}}{g_{s t}} .
$$

$\mathrm{BC}(i)$ is the betweenness centrality of customer $i, g_{s t}$ represents the number of all shortest paths from people $s$ to people $t$, and $g_{s t(i)}$ represents the number of shortest paths from people $s$ to people $t$ through customer $i$.

According to the above analysis, the customer with a large degree centrality, eigenvector centrality, and betweenness centrality can help marketing information spreading rapidly and broadly and also effectively influence on the purchase decision of other potential customers in the social network. Such customers may create greater value to the marketing communication of company. Therefore, it would be more important compared to the other customers in the relationship with the firm.

The marketing diffusion value of the $i^{\text {th }}$ customer is measured as follows:

$$
\operatorname{MDV}(i)=\alpha_{3} * \mathrm{DC}(i)+\beta_{3} * \operatorname{PR}(i)+\gamma_{3} * \mathrm{BC}(i)
$$

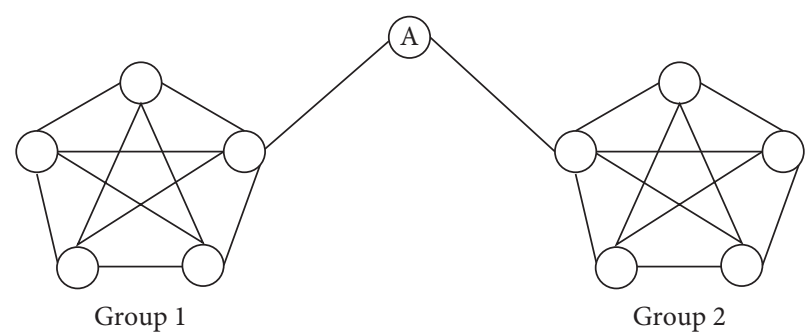

FIgURE 6: Schematic diagram of betweenness centrality of nodes.

$\operatorname{MDV}(i)$ is the marketing information diffusion value of customer $i, \mathrm{DC}(i)$ is the degree centrality of customer $i$; $\mathrm{PR}(i)$ is PageRank value of customer $i$; and $\mathrm{BC}(i)$ is the betweenness centrality of customer $I$. It is assumed here that $\alpha_{3}=\beta_{3}=\gamma_{3}=1$, so the marketing diffusion value of the $i$ th customer is calculated as follows:

$$
\operatorname{MDV}(i)=\mathrm{DC}(i)+\operatorname{PR}(i)+\mathrm{BC}(i) .
$$

3.2.4. Integrated Customer Value Model. Based on the analysis of customer behavior characteristics in mobile Internet era, this paper analyzes the customer value from three aspects of purchase value (PV), interactive value (IV), and marketing diffusion value (MDV) and builds the integrated customer value model by combining the RFM model and complex network theory. Among them, purchase value $(\mathrm{PV})$ is measured by transaction relationship duration (TRD), purchase frequency (PF), and average consumption amount (APM); interactive value (IV) is measured in two dimensions of comment value (CV) and sharing value (SV). The comment value (CMV) is measured by the latest comment time (LCT), comment frequency (CF), favorable gate (FR), and online comment content quality (CQ); sharing value (SV) is measured by the latest sharing time length (LST), willingness to share (SW), and sharing frequency (SF). The marketing diffusion value (MDV) is measured by PageRank value (PR), degree centrality (DC), and betweenness centrality (BC). The customer value model in the mobile Internet era is shown in Figure 7.

The mathematical model of the customer value in the mobile Internet era is shown in formula (22), and the description of variables are shown in Table 2.

$$
\begin{aligned}
& \mathrm{CV}(i)=\alpha * \mathrm{PV}(i)+\beta * \operatorname{IV}(i)+\gamma * \operatorname{MDV}(i) \\
& \left\{\begin{array}{l}
\mathrm{PV}(i)=\mathrm{TRD}(i)+\operatorname{PF}(i)+\operatorname{APM}(i) \\
\operatorname{IV}(i)=\mathrm{CMV}(i)+\operatorname{SV}(i)=(\mathrm{LCT}(i)+\mathrm{CF}(i)+\mathrm{FR}(i)+\mathrm{CQ}(i)) \\
+(\operatorname{LST}(i)+\operatorname{SW}(i)+\operatorname{SF}(i)) \\
\operatorname{MDV}(i)=\mathrm{DC}(i)+\operatorname{PR}(i)+\mathrm{BC}(i)
\end{array}\right.
\end{aligned}
$$




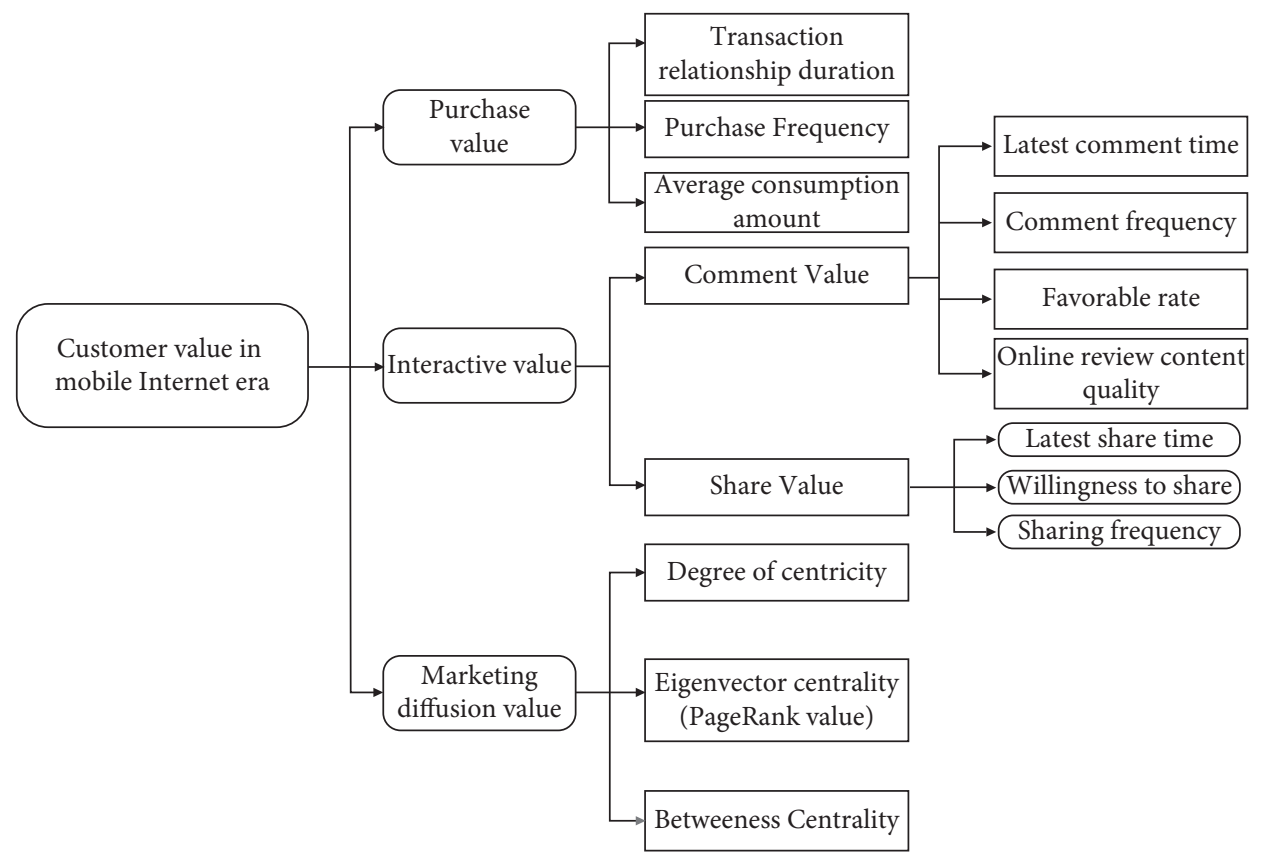

FIGURE 7: Integrated model of the customer value in the mobile Internet era.

TABLE 2: The description of variables in the mathematical model.

\begin{tabular}{|c|c|}
\hline Variable name & Description \\
\hline $\mathrm{CV}(i)$ & The value of the $i$ th customer in the statistical period \\
\hline $\mathrm{PV}(i)$ & Purchase value of the $i$ th customer in the statistical period \\
\hline $\operatorname{IV}(i)$ & Interactive value of the $i$ th customer in the statistical period \\
\hline $\operatorname{MDV}(i)$ & Marketing diffusion value of the $i$ th customer in the statistical period \\
\hline $\operatorname{CMV}(i)$ & Comment value of the $i$ th customer in the statistical period \\
\hline $\mathrm{SV}(i)$ & Sharing value of the $i$ th customer in the statistical period \\
\hline $\operatorname{TRD}(i)$ & Transaction relationship duration of the $i$ th customer in the statistical period \\
\hline $\mathrm{PF}(i)$ & Purchase frequency of the $i$ th customer in the statistical period \\
\hline $\operatorname{APM}(i)$ & Average consumption amount of the $i$ th customer in the statistical period \\
\hline $\mathrm{LCT}(i)$ & Interval between the $i$ th customer's latest comments in the statistical period \\
\hline $\mathrm{CF}(i)$ & Frequency of comments made by the $i$ th customer during the statistical period \\
\hline $\operatorname{FR}(i)$ & The favorable rate of the $i$ th customer's comments during the statistical period \\
\hline $\mathrm{CQ}(i)$ & The quality of comments made by the $i$ th customer during the statistical period \\
\hline $\operatorname{LST}(i)$ & The latest sharing interval of the $i$ th customer in the social network during the statistical period \\
\hline $\operatorname{SW}(i)$ & The $i$ th customer's sharing willingness in the social network during the statistical period \\
\hline $\mathrm{SF}(i)$ & The $i$ th customer's sharing frequency in the social network during the statistical period \\
\hline $\operatorname{PR}(i)$ & PageRank value of the $i$ th customer during the statistical period \\
\hline $\mathrm{DC}(i)$ & Degree centrality value of the $i$ th customer during the statistical period \\
\hline $\mathrm{BC}(i)$ & Betweenness centrality value of the $i$ th customer during the statistical period \\
\hline$\alpha$ & The weight of customer purchase value \\
\hline$\beta$ & The weight of customer interactive value \\
\hline$\gamma$ & The weight of customer marketing diffusion value \\
\hline
\end{tabular}

For the weights of purchase value, interactive value, and marketing diffusion value in the model, this paper flexibly adjusts the corresponding parameter of $\alpha, \beta$, and $\gamma$ to identify value of customers as a partner of company under different marketing scenarios as shown in Figure 8.

Scenario I: new product introduction period. The main goal of this stage is to quickly establish market awareness of the new product. In this scenario, parameter $\gamma$ takes a larger value than parameter $\alpha$ and parameter $\beta$ when identifying the customer value. The customer who has high marketing diffusion value usually is an opinion leader or information bridge and plays an important role in the marketing communication. If the role of such customers can come into play, the marketing information of new products will spread virally in a short period of time and be known to the vast potential market. Moreover, such customers will affect the adoption of new products/services of the potential market.

Scenario II: product growth period. At this stage, market starts to accept the products and profits increase significantly. The focus of marketing objectives is shifted from 


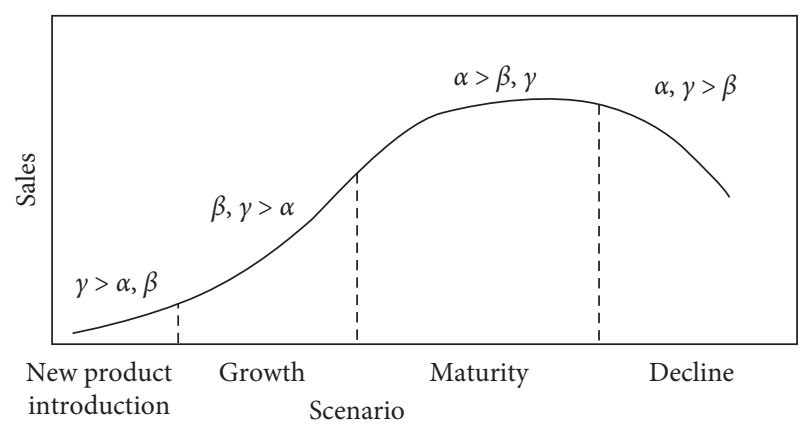

FIGURE 8: Model parameter setting in different scenery.

establishing product awareness to persuading more consumers to purchase product or service. The postpurchase sharing and comment from the purchased customers play an increasingly important role in the online purchase decisionmaking of potential consumers in the era of mobile Internet. Before purchasing, people often take it as an information clue to judge the products and services and then decide whether to buy or not, so in this scenario, parameter $\beta$ and parameter $\gamma$ are more important than parameter $\alpha$ when identifying customer value.

Scenario III: product maturity period. At this stage, products of the company have been widely accepted by the market, while potential growth of sale has slowed down. It is the key to keep the satisfaction and loyalty of existing customers and increase their trading behavior in this situation. Therefore, parameter $\alpha$ is more important than parameter $\beta$ and parameter $\gamma$ when identifying value of customers.

Scenario IV: product decline period. Sales volume and profit of the product are constantly declining due to the fierce competition in the Red Sea market. The company has to extract the remaining value of the loyal customers, in the meanwhile, develop new product line, and create a new market. In such situation, loyal customers with high network structure centrality are of great value for company, and they help the company promote new products to market besides continual transaction contributions. Therefore, parameter $\alpha$ and parameter $\gamma$ are more important than parameter $\beta$ when identifying customer value.

\section{Customer Value Model Application}

Each customer's value can be identified and ranked by the above customer value model. On the other hand, the three variables of purchase value, interactive value, and marketing diffusion value in the model can be used as the characteristics of customer behavior segmentation, which lays the foundation for differentiated customer relationship management strategies in the mobile Internet era.

The customers purchase, interactive, and marketing diffusion value can be identified individually as the variables in the customer value model, and the average value of each variable is taken as the basis for dividing their high and low, that is, $\mathrm{PV}(i)>\overline{\mathrm{PV}}$ represents higher purchase value; $\mathrm{PV}(i)$ $<\overline{\mathrm{PV}}$ indicates lower purchase value; $\mathrm{IV}(i)>\overline{\mathrm{IV}}$ indicates higher interactive value, $\operatorname{IV}(i)<\overline{\mathrm{IV}}$ indicates lower interactive value; $\mathrm{MDV}(i)>\overline{\mathrm{MDV}}$ indicates higher marketing diffusion value; and $\mathrm{MDV}(i)<\overline{\mathrm{MDV}}$ indicates lower marketing diffusion value. If the average value of a single category of customer value is greater than the total average value, it is marked as "†"; otherwise, it is marked as " $\downarrow$." Based on the three variables of the purchase value, interactive value, and marketing behavior value, the customer segmentation matrix in the mobile Internet is constructed, which is divided into 8 types of customers. This paper analyzes the customer value characteristics and differentiated marketing strategies of the eight types of customer groups as follows:

Type 1 (PV $\uparrow \mathrm{IV} \uparrow \mathrm{MD} \uparrow)$ : this kind of customer is the most valuable customer for the company. They not only keep a long-term trade partnership with company, and have high economic value, but also have high influence and activity in the social network. They have sufficient cognition and trust in products and services of company, and often follow the news of company, participate brand marketing activities, bring positive word-ofmouth, and even influence other people (potential customers) in their brand choice and purchase decision by means of their own social circle. Such customers make a great contribution in the relationship with the company. Therefore, the company needs to devote more marketing resources to carefully keep the sustainable relationship with such customers, even design one-to-one customized marketing strategy, and provide specific VIP services for them.

Type 2 (PV $\downarrow I V \uparrow M D \uparrow)$ : This type of customer has a high interactive value and marketing diffusion value, and the purchase value is low. Such customers have special important position in the relationship with company in the era of mobile Internet. They are important partners of the company in marketing communication. Companies can leverage the social activity and influence of such customers in the social network to promote brand and inspire a sense of trust of the potential customers on the brand. At the same time, it should provide personalized recommending services and price discounts for such customers to remedy their lack of purchasing power and transform them into type 1 customers.

Type 3 (PV $\uparrow \mathrm{IV} \downarrow \mathrm{MD} \uparrow$ ): such customers have high purchase value and high network structure position with high impact on marketing diffusion, but the interactive value is less. They are the key customers to be developed for the company. The company can offer the attractive rewards such as price discounts and special gifts to stimulate such kind of customer more participation in comment and sharing in product experience, so that the network influence of such customers can be as maximized as possible.

Type 4 (PV $\uparrow \mathrm{IV} \uparrow \mathrm{MD} \downarrow)$ : such customers have higher purchase and interactive value, but lower marketing diffusion value. Such customers take active part in comment and sharing of products and services in the 
social network and constantly directly contribute to the profits of the company. Although they do not have such high influence, they are still important customers for the company. Company can take the targeted method such as@customer, to increase this kind of customers' exposure rate and influence in the social network.

Type 5 (PV $\downarrow$ IV $\downarrow M D \uparrow)$ : this kind of customer has high network structure position with high marketing diffusion value. They are often opinion leaders or Internet celebrities with a large number of followers in the network, but their purchasing power is weak, online interaction is not active, and they cannot effectively influence other potential customers through network interaction. Such customers are few, but they are concealed VIP customers who can bring huge profits to the company in the era of mobile Internet. For such important customers, the company should motivate their enthusiasm to interact, share a good shopping experience in the social network, and maximize their marketing diffusion value. On the other hand, the company should communicate frequently with them to collect the purchase feedback and improve their satisfaction and also take precautions to avoid negative comments made by such customers, which may cause a large scale of brand crisis in public image.

Type 6 (PV $\uparrow \mathrm{IV} \downarrow \mathrm{MD} \downarrow)$ : such customers are regarded as high-quality under the traditional business environment; they constantly buy products and services and create direct purchase value for the company. But they have low online activity and less influence in the social network. They are a low-key group in the online society. For such customers, the company need to create opportunities to communicate with them online and make them willing to comment and share perfect product experience in the social network and gradually develop the network influence while continuing to play their purchasing power advantage.

Type 7 (PV $\downarrow$ IV $\uparrow \mathrm{MD} \downarrow)$ and type 8 (PV $\downarrow I V \downarrow M D \downarrow)$ of customers have a lack of purchasing power, low brand loyalty, and low network value. For companies, they are the least valuable customers. The possibility of the new customers in the introduction period should be considered for such kind of customers. If it is a customer who has been in this value layer for a long time, the company can adopt quitting strategy to improve the efficiency of resource allocation in the customer relationship management.

\section{Discussion}

The interaction and connection among people have bloomed in the era of mobile Internet. Consumer behavior is no longer a simple online shopping, but also shows a strong social characteristic such as product and service comment and sharing, as well as being cooperative with company in the marketing information communication with the public. The emphasis of customer relationship management will shift from how to maximize customer purchase to stimulate the interaction enthusiasm of social network members centering on the brand and give full play to the huge network connection value of customers. This paper explores the understanding of customer value in such a new situation of customer relationship management. Based on the analysis of the features of consumer behavior in the mobile Internet, this paper proposes an integrated customer value model combining the complex network theory and RFM model and identifies the customer value from three dimensions of purchase value, interactive value, and marketing diffusion value with 13 indicators. And then, this paper analyzes the application of the model from the perspective of customer segmentation and puts forward eight types of customer clusters and the corresponding differentiated customer relationship management strategy in the era of mobile Internet.

This study enriches the theory of customer value in the field of customer relationship management and also helps company better practice the innovation and change in the management of relationship with customer in mobile Internet era. However, there are still some limitations that offer potentially fruitful research avenues. First, this study is exploratory in nature and based on qualitative methodology and builds a theoretical model of customer value by qualitative analysis on the consumer behavior combing RFM model and complex network theory in the mobile era. For further study, it is can be tested and modified to improve the credibility and trustworthiness of the findings by utilizing empirical methodology in specific industry. Second, this study did not offer the exact value of weight of variables in the customer value model, and future research could develop it by inducing the Delphi method, analytic hierarchy process, and neural network.

\section{Data Availability}

The data used to support the findings of this study are available from the corresponding author upon request.

\section{Conflicts of Interest}

The authors declare that they have no conflicts of interest.

\section{Acknowledgments}

This study was supported by the project "Vocational education Reform and Innovation" under grant no. HBKC217187 and "Humanity and Social Science Planning Foundation of Ministry of Education of China" under grant no. 20YJA630020.

\section{References}

[1] L. Ryals, "Making customer relationship management work: the measurement and profitable management of customer relationships," Journal of Marketing, vol. 69, no. 4, pp. 252-261, 2005.

[2] J. J. Sviokla and P. B. Shapir, "Build customer relationships that last," Harvard Business Review, vol. 6, pp. 110-123, 1994. 
[3] F. F. Reichheld, "Loyalty-based management," Harvard Business Review, vol. 2, pp. 54-62, 1993.

[4] G. R. Bitran and S. V. Mondschein, "Mailing decisions in the catalog sales industry," Management Science, vol. 42, no. 9, pp. 1364-1381, 1996.

[5] P. D. Berger and N. I. Nasr, "Customer lifetime value: marketing models and applications," Journal of Interactive Marketing, vol. 12, no. 1, pp. 17-30, 1998.

[6] D. C. Schinittlein, G. M. Donald, and C. Richard, "Counting your customers: who are they and what will they do next?" Management Science, vol. 33, no. 1, pp. 1-24, 1987.

[7] P. S. Fader, B. G. S. Hardie, and K. L. Lee, “"Counting your customers" the easy way: an alternative to the Pareto/NBD model," Marketing Science, vol. 24, no. 2, pp. 275-284, 2005.

[8] A. Hughes, "Boosting response with RFM," Marketing Tools, vol. 5, pp. 4-10, 1994.

[9] F. Safari, N. Safari, and G. A. Montazer, "Customer lifetime value determination based on RFM model," Marketing Intelligence \& Planning, vol. 34, no. 4, pp. 446-461, 2016.

[10] V. A. Zeithaml, "Consumer perceptions of price, quality, and value: a means-end model and synthesis of evidence," Journal of Marketing, vol. 52, no. 3, pp. 2-22, 1988.

[11] P. M. Cole and R. E. Wayland, Customer Connection, Harvard Business School Press, Boston, MA, USA, 1997.

[12] W. Achim, R. Thomas, and G. G. Hans, "Value creation in buyer-seller relationships: theoretical considerations and empirical results from a supplier's perspective," Industrial Marketing Management, vol. 4, pp. 365-377, 2001.

[13] L. Q. Luu, S. Longo, M. Cellura, and E. R. Sanseverino, "A review on consequential life cycle assessment in the power sector," International Journal of Sustainable Development and Planning, vol. 15, no. 8, pp. 1157-1168, 2020.

[14] R. Varadarajan and K. Kalaignanam, "Customers as coproducers: implications for marketing strategy effectiveness and marketing operations efficiency," in The Service-Dominant Logic of Marketing: Dialog, Debate, and Directions, F.Robert, Lusch, and S. L. Vargo, Eds., pp. 166-180, M. E. Sharpe. Inc, Armonk, NY, USA, 2006.

[15] V. Selicati and N. Cardinale, "The benefits in coupling exergy analysis and life cycle assessment in the context of sustainable manufacturing for industry 4.0: a real industrial case," International Journal of Heat and Technology, vol. 39, no. 1, pp. 12-22, 2021.

[16] N.-C. Hsieh, "An integrated data mining and behavioral scoring model for analyzing bank customers," Expert Systems with Applications, vol. 27, no. 4, pp. 623-633, 2004.

[17] B. Sohrabi and A. Khanlari, "Customer lifetime value (CLV) measurement based on RFM model," The Iranian Accounting and Auditing Review, vol. 14, no. 47, pp. 7-20, 2007.

[18] S. F. King, "Citizens as customers: exploring the future of CRM in UK local government," Government Information Quarterly, vol. 24, no. 1, pp. 47-63, 2007.

[19] Y.-M. Li, C.-H. Lin, and C.-Y. Lai, "Identifying influential reviewers for word-of-mouth marketing," Electronic Commerce Research and Applications, vol. 9, no. 4, pp. 294-304, 2010.

[20] Y. Zhang, E. T. Bradlow, and D. S. Small, "Predicting customer value using clumpiness: from RFM to RFMC," Marketing Science, vol. 34, no. 2, pp. 179-307, 2015.

[21] S.-T. Li, L.-Y. Shue, and S.-F. Lee, "Business intelligence approach to supporting strategy-making of ISP service management," Expert Systems with Applications, vol. 35, no. 3, pp. 739-754, 2008.
[22] S.-A. Lumsden, S. Beldona, and A. M. Morrison, "Customer value in an all-inclusive travel vacation club: an application of the RFM framework," Journal of Hospitality \& Leisure Marketing, vol. 16, no. 3, pp. 270-285, 2008.

[23] J.-J. Jonker, N. Piersma, and R. Potharst, "A decision support system for direct mailing decisions," Decision Support Systems, vol. 42, no. 2, pp. 915-925, 2006.

[24] D. R. Chialvo, "Critical brain networks," Physica A: Statistical Mechanics and Its Applications, vol. 340, no. 4, pp. 756-765, 2004.

[25] A. R. M. Teutle, "Twitter: network properties analysis," in Proceedings of the 2010 20th International Conference on Electronics, Communication and Computer, Cholula, Puebla, Mexico, February 2010.

[26] W. Galuba, K. Aberer, D. Chakraborty, Z. Despotovic, and W. Kellere, "Outtweeting the Twitters-predicting information cascades in microblogs," in Proceedings of the 3rd Workshop on Online Social Network, Boston, MA, USA, 2010.

[27] D. J. Watts and S. H. Strogatz, "Collective dynamics of'smallworld' networks,” Nature, vol. 393, no. 6684, pp. 440-442, 1998.

[28] S. Milgram, “The small-world problem," Psychology Today, vol. 2, p. 60, 1997.

[29] A. L. Barabási, "The origin of bursts and heavy tails in human dynamics," Nature, vol. 435, pp. 207-211, 2005.

[30] R. Albert, H. Jeong, and A.-L. Barabási, "Error and attack tolerance of complex networks," Nature, vol. 406, no. 6794, pp. 378-382, 2000.

[31] D. S. Callaway, M. E. J. Newman, S. H. Strogatz, and D. J. Watts, "Network robustness and fragility: percolation on random graphs," Physical Review Letters, vol. 85, no. 25, pp. 5468-5471, 2000.

[32] R. Cohen, K. Erez, D. Ben-Avraham, and S. Havlin, "Breakdown of the Internet under intentional attack," Physical Review Letters, vol. 86, no. 16, pp. 3682-3685, 2001.

[33] J. Weng, E. P. Lim, and J. Jiang, "Twitter rank: finding topicsensitive influential twitters," in Proceedings of the Third ACM International Conference on Web Search and Data Mining, ACM Press, New York, NY, USA, February 2010.

[34] S. Vitali, J. B. Glattfelder, and S. Battiston, "The network of global corporate control," PLoS One, vol. 6, Article ID e25995, 2011.

[35] X. Ren and L. Y. Lu, "Overview of the sorting methods of important network nodes," Chinese Science Bulletin, vol. 59, no. 13, pp. 1175-1197, 2014.

[36] V. Saprikis, "Modeling users' acceptance of mobile social commerce: the case of 'Instagram checkout'," Electronic Commerce Research, 2021.

[37] P. C. Verhoef, A. T. Stephen, P. K. Kannan et al., "Consumer connectivity in a complex, technology-enabled, and mobileoriented world with smart products," Journal of Interactive Marketing, vol. 40, pp. 1-8, 2017.

[38] P. Yu, "Contextual marketing in the mobile internet environment: a literature review and prospects," Foreign Economics \& Management, vol. 41, no. 5, pp. 3-16, 2019.

[39] M. X. Huang, J. Y. Liao, and N. Zhou, "'Can community experience improve consumers' brand loyalty?" research on the effect and influence mechanism of different experience components," Nankai Management Review, vol. 3, pp. 151$160,2015$.

[40] S. Lee and J. Y. Choeh, "Predicting the helpfulness of online reviews using multilayer perceptron neural networks," Expert Systems with Applications, vol. 41, no. 6, pp. 3041-3046, 2014. 
[41] C. D. Zheng, Q. Han, and H. Wang, "How do the comments of Internet water army influence your purchase intention?" Nankai Management Review, vol. 18, no. 1, pp. 89-97, 2015.

[42] S. Y. Gong, X. Liu, and P. Zhao, "How does online consumer reviews affect product sales? empirical research based on online book review," China soft science, vol. 6, pp. 171-183, 2013.

[43] R. Q. Wei, Research on the Influence Mechanism of User Generated Content on Online Purchase under Bilateral Platform Environment, Beijing Jiaotong University, Beijing, China, 2016.

[44] E. Akar and T. Dalgic, "Understanding online consumers' purchase intentions: a contribution from social network theory," Behaviour \& Information Technology, vol. 37, no. 5, pp. 473-487, 2018.

[45] C. C. Chen and Y.-D. Tseng, "Quality evaluation of product reviews using an information quality framework," Decision Support Systems, vol. 50, no. 4, pp. 755-768, 2011.

[46] D. J. Watts and P. S. Dodds, "Influentials, networks, and public opinion formation," Journal of Consumer Research, vol. 34, no. 4, pp. 441-458, 2007.

[47] X. Liu, D. He, L. Yang, and C. Liu, "A novel negative feedback information dissemination model based on online social network," Physica A: Statistical Mechanics and Its Applications, vol. 513, pp. 371-389, 2019.

[48] X. Li, Empirical Research on Enterprise Microblog Marketing and Information Waterfall Communication Based on Social Network Analysis, Beijing University of Posts and Telecommunications, Beijing, China, 2013.

[49] R. S. Burt, M. J. Minor, and R. D. Alba, Applied Network Analysis: A Methodological Introduction, Sage Publications, California, USA, 1983.

[50] L. C. Freeman, "Centrality in social networks conceptual clarification," Social Networks, vol. 1, pp. 215-239, 1979.

[51] S. Brin and L. Page, "The anatomy of a large-scale hypertextual web search engine," Computer Networks and ISDN Systems, vol. 30, no. 1-7, pp. 107-117, 1998.

[52] E. Estrada and J. A. Rodríguez-Velázquez, "Subgraph centrality in complex networks," Physical Review. E, Statistical, Nonlinear, and Soft Matter Physics, vol. 71, Article ID 056103, 2005.

[53] L. C. Freeman, "A set of measures of centrality based on betweenness," Sociometry, vol. 40, no. 1, pp. 35-41, 1997. 